\title{
Incidental and Intentional Instruction on Discussion Techniques: Assessing Complexity Issue
}

\author{
Massoud Rahimpour ${ }^{1,2}$ and Zohre Mohamadi ${ }^{3}$ \\ ${ }^{1}$ The University of Queensland, QLD 4072, Australia \\ ${ }^{2}$ University of Tabriz, Tabriz, Iran \\ ${ }^{3}$ English Teaching Department, Islamic Azad University of Karaj, Karaj, Iran \\ Correspondence should be addressed to Massoud Rahimpour, m.rahimpour@uq.edu.au
}

Received 21 December 2011; Accepted 12 February 2012

Academic Editors: B. W. Baldwin, C. Dunst, and Y. Xie

Copyright ( $) 2012$ M. Rahimpour and Z. Mohamadi. This is an open access article distributed under the Creative Commons Attribution License, which permits unrestricted use, distribution, and reproduction in any medium, provided the original work is properly cited.

\begin{abstract}
Although both incidental and intentional instructions provide a medium for acquiring the communicative language, they suffer from a number of oversimplifications. Whereas the majority of studies in these paradigms have addressed second language (L2) grammatical development, there has been a growing interest in the effect of these types of instruction on pragmatic development, conversation gambits, and speech acts. The purpose of the present paper is to compare these types of instruction in promoting learning of discussion techniques. Learner performance was analyzed on the basis of the mean occurrence of discussion techniques (giving opinions and presenting series of arguments) in implicitly and explicitly instructed group using independent $t$-test. The quality of leaner language produced in each group was further analyzed in terms of complexity measuring the complexity of utterances and length of the turns. The results were all in favor of intentional instruction.
\end{abstract}

\section{Introduction}

Along with the pedagogical developments, there was also considerable growth in the relatively new field of second language acquisition, where the focus was on the premise that naturalistic exposure to language and use of language, which drives forward interlanguage (the structural development of language), was a prerequisite for the development of language [1].

Although both implicit and explicit instructions provide a medium for acquiring the communicative language, they suffer from a number of oversimplifications. However, the potentials of each instruction type in creating such a medium were not investigated in exhaustive detail, and it is left as a potentially interesting topic for further research, see the work by Ellis Barkhuizen [2-5] and Bygate $[6,7]$.

Early studies examined the relationship between learners' implicit and explicit knowledge. Ellis [8] has distinguished implicit and explicit learning of L2, and he sees the former as primary. Explicit knowledge is typically the end product of acquisition, not the cause. The relation between two types of knowledge was discussed in terms of the interface between them. "According to the non-interface position, implicit and explicit L2 knowledge involve different parts of the brain and are accessed for performance by different processes, either automatic or controlled in its pure form. This position rejects the possibility of transforming explicit knowledge directly into implicit knowledge and implicit knowledge into explicit knowledge," see Ellis [8], the problem with these studies was that they were all correlational in design. There has been no empirical research for the reason that researchers have failed to give due consideration to implicit and explicit construct.

Later studies on explicit and implicit instruction were on how linguistic aspect of language including vocabulary learning and acquisition, phonology, and sound system of language where as discourse studies have been neglected within this dichotomous methodology of language teaching. The way that learners manage their conversation to express their meaning at informational level has influential influence on their interlanguage as they use their language potential in turn, discussion, and discourse management [9]. Whether instruction in its incidental or intentional sense has any role in pushing learners to have extended and complex utterances is still open to research. It is widely argued that 
different types of instruction facilitate the acquisition of communicative language to different degrees through providing different contexts for the occurrence of negotiation of meaning through discussion which is believed to have facilitative role in language acquisition [10]. Whereas the majority of studies in these paradigms have addressed L2 grammatical development, there has been a growing interest in the effect of these types of instruction on pragmatic development, conversation gambits, and speech acts.

Discussion as a general function of language is broken up into a set of smaller functions. For defining and clarifying the conversational techniques, a package of language resources including words, phrases, and fixed expressions to handle each subsection is studied. Two discussion techniques, namely, giving opinion and presenting series of argument were selected according to the fact that in the materials that the intermediate level students mostly encounter generally deal with giving opinion and presenting series of argument. Whereas the majority of studies in these paradigms have addressed L2 grammatical development, there has been a growing interest in the effect of these types of instruction on pragmatic development, conversation gambits, and speech acts. The purpose of the present study is to compare these types of instruction in promoting learning discussion techniques. The quantity discussion techniques can be examined by the incidence of discussion techniques and the quality of discussion can be examined by length of turns, complexity of the utterances. Swain cited in Nakahama et al. [11] argues that nonnative speakers (NNS) need pushed output, which requires the on-line production of longer, more complex utterances, for acquisition to take place. Pushed output can be examined through looking for some evidence in terms of the length of turns, the complexity of utterances. The data were quantitatively analyzed to explore differences in interactions in terms of the above-mentioned perspectives developed in each type group. The purpose of the present study is to compare these types of instruction in promoting learning discussion techniques. The quantity discussion techniques can be examined by the incidence of discussion techniques and the quality of discussion can be examined by length of turns, complexity of the utterances $[11,12]$.

\section{The Research Questions}

Considering the points mentioned in the preceding section about instruction typology and its effect on providing opportunities in promoting learning of discussion techniques, the researchers set the following questions.

(1) Is there any statistically significant difference between explicit and implicit instruction in terms of the quantity of discussion techniques in participant performances?

(2) Is there any statistically significant difference between explicit and implicit instruction in terms of the quality of discussion in terms of the length of the turns?
(3) Is there any statistically significant difference between explicit and implicit instruction in terms of the quality of discussion in terms of the complexity of the utterance?

\section{Method}

3.1. Participants. The participants in the present study were 16 male and female nonnative speakers (NNS) at the intermediate level of language proficiency whose first language (L1) is Persian. They were all between 18 and 23 years old. The participants were approximately at the same level of language proficiency as their oral ability was measured on the interview which was designed on the basis of the curriculum through which they had learned English and measured according to Foreign Service Institute (FSI) rating scale (oral proficiency rating system). They were randomly assigned to explicitly instructed group and implicitly instructed group.

\subsection{Instrumentation}

3.2.1. Interview. FSI rating was used to ensure homogeneity of participants on the basis of language proficiency so that any significant differences could be attributed to group membership variable rather than preexisting differences. Students with one standard deviation above and below the mean are considered as intermediate participants.

3.2.2. Speaking Tasks. Speaking tasks which were the medium of the study were selected on the basis of topic familiarity and language familiarity. Tasks were taken from the materials the participants worked on and selected on the basis of the participants' answers to a questionnaire (Appendix A) designed to elicit information about topic familiarity to include tasks on the basis of the topics that participants feel confident at as it is believed individual interests may affect task performance Dornyei and Kormos [13], and modified and evaluated according to the comments made by participants' teachers on a questionnaire (Appendix B) designed for determining the appropriateness of the tasks taken from Nunan $[14,15]$. Then, the modified tasks were pre-evaluated with two participants similar to the intended participants as their oral ability was measured by the designed interview.

3.3. A Framework for Discussion Techniques. Discussion as a general function of language is broken up into a set of smaller functions. For defining and clarifying the conversational techniques, a package of language resources including words, phrases, and fixed expressions to handle each subsection is collectively given. Two discussion techniques, namely, giving opinion and presenting series of argument were selected according to the fact that the materials that the intermediate level students mostly encounter generally deal with giving opinions and series of arguments.

3.4. Nature of Implicit Instruction Group. Instead of teaching students the discussion techniques explicitly, the opportunities for imposing students to the input which includes 
those techniques were provided. Ellis [16] states implicit instruction involves creating a learning environment that is enriched with the target feature, but without drawing learners' explicit attention to it. In real-word contexts, students may encounter materials only for which they need to have comprehension and then required action. Explicit instruction is one way to draw students' attention to required target language elements (here discussion techniques) but not the only way. Input frequency and exposing students to the input which includes the target elements (implicit instruction) can also be an option. For this purpose (implicit instruction) materials which are mostly talk shows were selected in ways that are compatible with topic and language familiarly criteria mentioned. To satisfy the topic familiarity criterion students were given questionnaire to identify the topic familiarity issues. With the same respect, language familiarity and complexity are tested with how well students could understand the talk show and provide the summary and main issues in the task evaluation phase of the study.

3.5. Nature of Explicit Instruction Group. In the explicit instruction group, students were explicitly taught the discussion techniques mentioned above. This explicit instruction includes explanation of the techniques and providing the examples for their use.

\section{Procedure}

Prior to conducting the research, the participants were informed about what they were going to go through. They had been given a checklist in order to determine their background knowledge and the tasks that they were more confident at (topic familiarity). The sample tasks were taken from the materials that the participants had studied on the basis of their' answers to checklist. Then, the teachers were given the sample tasks and asked to evaluate the tasks according to the checklist provided to determine the appropriateness (Appendix B) of tasks for the intended participants taken from Nunan $[14,15]$. An evaluation of tasks was administered by a similar group to the intended one selected on the basis of their scores in the interview. The purpose of this evaluation was to see whether tasks would lend themselves for discussion between students. By so doing, the researchers could have reliable sources of decision making based on the selected tasks. After the selection of tasks, each participant was asked to work with his or her partner within the group. The tasks were introduced to the participants by their teacher.

4.1. Instruction in Explicit Group. The teacher is given a lesson plan for instructing the mentioned discussion techniques. After explicit instruction providing students examples about language resources by which they could implement discussion techniques, the teacher provided opportunities through group work and pair work to apply the techniques while they were communicating about topics that were chosen according the topic familiarly and the procedure mentioned in previous sections.
TABle 1: Descriptive statistics on discussion techniques across two groups.

\begin{tabular}{lccccc}
\hline & $\begin{array}{c}\text { Group } \\
\text { membership }\end{array}$ & $N$ & Mean & $\begin{array}{c}\text { Std. } \\
\text { deviation }\end{array}$ & $\begin{array}{c}\text { Std. error } \\
\text { mean }\end{array}$ \\
\hline Discussion & Explicit & 8 & 8.7500 & 3.57571 & 1.26421 \\
techniques & Implicit & 8 & 2.3750 & .91613 & .32390 \\
\hline
\end{tabular}

4.2. Procedure in Implicit Group. Instead of teaching students explicitly the selected discussion techniques in implicit group, the teachers were asked to provide input as much as possible. To this end, materials which are mostly talk shows were selected in ways that are compatible with topic and language familiarly criteria mentioned. To satisfy the topic familiarity criterion students were given questionnaire to identify the topic familiarity issues. With the same respect, language familiarity and complexity are tested with how well students could understand the talk show and provide the summary and main issues in the pretest phase of the study. Before playing talk shows, the teacher was asked to have a warmup on the basis of the topics of talk shows. While talk shows were played, students were asked to listen carefully. After receiving the discussion techniques as input through talk shows, students were asked to work in pairs and groups. The purpose was providing opportunities to use the input that they have received. Receiving discussion techniques in materials in the form of talk shows is what we mean by input frequency and exposure to targeted language elements. The teacher was not supposed to do anything to bring students' attention on discussion techniques in talk shows.

\section{Design}

The performances on explicit and implicit teaching groups were audiotaped for data analysis. Then, each recorded interaction was transcribed. After the data collection was completed, the researcher reviewed the transcription to check the identified techniques.

\section{Data Analysis}

The data were analyzed both quantitatively and qualitatively in order to identify different ways in which selected discussion techniques in explicit and implicit group were used. In order to establish comparability, all interactions were normalized to 10 minutes.

6.1. Quantity of Discussion Techniques in Each Group. The quantitative analysis involved examining overall patterns of interaction, including the ways the selected techniques were used. Two raters independently coded the transcriptions and discussion techniques. Interrater reliability for discussion techniques was calculated to indicate the reliability of the procedure in identification of the discussion techniques. To compare discussion techniques in two different types of interactions $t$-test was used, treating occurrences like test score and calculating a mean for each type of interaction (explicitly instructed and implicitly instructed groups). Table 1 provides descriptive statistic on the frequency of 
TABLE 2: Independent sample $t$-test on discussion techniques across two groups.

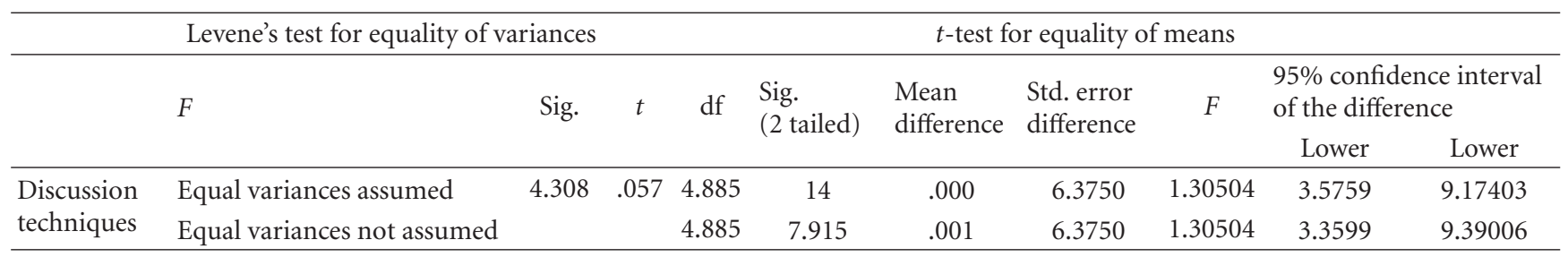

TABLE 3: Descriptive statistics on length of turn in each group.

\begin{tabular}{lccccc}
\hline & Group membership & $N$ & Mean & Std. deviation & Std. error mean \\
\hline Length of & Intentional & 8 & 13.0000 & 2.13809 & .75593 \\
turns & Incidental & 8 & 9.8750 & 1.24642 & .44068 \\
\hline
\end{tabular}

the occurrence of discussion techniques giving opinions and presenting series of arguments. Table 2 shows the significant value (sig. value) of mean comparison of discussion technique (.000) in each group is significant as it is less than .005 , the alpha level, the criteria mentioned by Farhady [17]. To see which group had more discussion techniques in its performance, Table 1 is recalled. By analyzing the mean difference of groups, one would see that the mean score for discussion technique (8.75) is greater in explicit group.

Comparing the quantity of discussion techniques in explicitly instructed and implicitly instructed group across tasks thus does not seem to tell the whole story. Attending to the overall numbers of discussion techniques masks important discourse dynamics at information level.

6.2. Length of the Turns. "A turn is defined as a stretch of speech of single interlocutor; back channels (e.g., uh-huh) are not considered to constitute turns unless they are uttered to answer the interlocutor's questions. The length of a turn was examined through the number of words per turn" [11]. $t$-test was used to compare the mean number of words per turn in performances in explicitly instructed and implicitly instructed groups. Table 3 shows the descriptive statistics on the length of turns in each group and Table 4 provides information on the test's probability value.

The sig. value is .003 assuming homogeneity of groups which is less than .005 rejecting the null hypothesis and approving the existence of significant difference. To see which group leads to lengthy utterances Table 3 is recalled. The mean number of occurrence of lengthy turns in intentional group is higher (13).

6.3. Complexity of the Utterances. "An utterance is defined as a single intonational contour, forming a single propositional or meaning unit, and bounded by brief pauses or interlocutor change. A turn could thus contain more than one utterance. For instance, utterances with one verbal construction is coded as S1 (e.g., well I've heard of Tokyo) and utterances with more than one verbal construction is coded as $\mathrm{S}^{+}$(e.g., uh, I don't need to work for a company)" [11]. t-test was used to compare the mean number of words per unit in performances in explicitly instructed and implicitly instructed groups. Table 5 shows descriptive statistics on complexity of utterances and Table 6 shows the research probability level. The sig. value is .001 assuming homogeneity of variances. Since it is less than research probability (.005), the third null hypothesis can be rejected. The significance differenced can be traced back by checking the descriptive statistics in Table 5. The mean number of complex utterances is greater in intentional group (9).

\section{Discussion}

As mentioned before, implicit instruction is directed at enabling learners to infer rules without awareness. That is, it seeks to provide learners with experience of specific exemplars of a rule or pattern while they are not attempting to learn. But it is also possible to envisage some types of direct intervention as being implicit. It is possible to determine a specific learning target feature but to mask this from the learners so that they are not aware of the target. This type of implicit instruction involves creating a learning environment that is enriched with the target feature, but without drawing learners' explicit attention to it. It seems that there is always a room for instruction even at the pragmatic and discourse level. As mentioned before mush research has been on grammar and vocabulary acquisition through either incidental or intentional. Discourse techniques as discourse markers can be a good start to examine these options in instruction at discourse and pragmatic level. Analyzing the occurrences of mere discourse techniques as a way to favor either type of instruction masks other discourse features. Second language acquisition (SLA) will benefit more from either type of instruction if they help learner to stretch their interlanguage. One way to measure this criterion is to see if intentional or incidental learning and in turn teaching helps learners to produce pushed output. And the quality of pushed output can be examined by analyzing the complexity of language learners have in their language as a result of incidental and intentional instruction. By 
TABLE 4: Independent $t$-test on length of turns in each group.

\begin{tabular}{|c|c|c|c|c|c|c|c|c|c|c|}
\hline & \multicolumn{2}{|c|}{ Levene's Test for Equality of Variances } & \multicolumn{8}{|c|}{$t$-test for Equality of Means } \\
\hline & \multirow[t]{2}{*}{$F$} & \multirow[t]{2}{*}{ Sig. } & \multirow[t]{2}{*}{$t$} & \multirow[t]{2}{*}{ df } & \multirow{2}{*}{$\begin{array}{l}\text { Sig. } \\
\text { (2 tailed) }\end{array}$} & \multirow{2}{*}{$\begin{array}{l}\text { Mean } \\
\text { Difference }\end{array}$} & \multirow{2}{*}{$\begin{array}{l}\text { Std. Error } \\
\text { Difference }\end{array}$} & \multirow[t]{2}{*}{$F$} & \multicolumn{2}{|c|}{$\begin{array}{l}\text { 95\% Confidence Interval } \\
\text { of the Difference }\end{array}$} \\
\hline & & & & & & & & & Lower & Lower \\
\hline \multirow{2}{*}{$\begin{array}{l}\text { Length Of } \\
\text { turns }\end{array}$} & Equal variances assumed & 3.377 & .087 & 3.57 & 14 & .003 & 3.1250 & .87500 & 1.24831 & 5.00169 \\
\hline & Equal variances not assumed & & & 3.57 & 11.2 & .004 & 3.1250 & .87500 & 1.20466 & 5.04534 \\
\hline
\end{tabular}

TABle 5: Descriptive statistics on complexity of language.

\begin{tabular}{lccccc}
\hline & Group membership & $N$ & Mean & Std. Deviation & Std. Error Mean \\
\hline Complex & intentional & 8 & 9.8750 & 2.10017 & .74252 \\
utterances & incidental & 8 & 6.1250 & 1.12599 & .39810 \\
\hline
\end{tabular}

analyzing the frequency of targeted feature and complexity of language in each group now it is clear that the intentional group which received instruction on discussion techniques used more discussion and more lengthy turns and more complex utterances. Whereas recent trend in SLA favors implicit instruction as there is an absence of intervention in learners' interlanguage and by emphasizing that learners' built-in syllabus may not comply with teachers' syllabus, the SLA enjoys instruction not at grammar development level (microlevel) but at macrolevel (discourse) in practice. This may be what Pennycook calls as incommensurability. There is a mismatch between pedagogical advances and practice at second language acquisition.

\section{Conclusion}

Along with new trends in SLA and foreign language learning (FLL), much research has addressed the truth values of the pedagogical advances at theoretical level. One of these areas is incidental learning and teaching. Much research has cleared up this typology of language teaching in grammar development and vocabulary acquisition. More research is needed to evaluate the efficiency of these two types at macrolevel including discourse and pragmatics. One of the areas at discourse level analysis is discourse markers. The results of this study were in the favor of intentional learning and in turn instruction both at occurrences of discussion techniques and using these techniques in having pushed extended output leading to more complex and lengthy turns at students' parts.

\section{Limitations}

This study suffers from a number of limitations which make generalizability of the results difficult. The first one is the small number of participants. If the same results are obtained by replicating the study, the results will be more reliable. The second is the nature of implicit instruction. Because participants' performance is affected by their listening ability, we cannot claim that the results in implicit instruction group and explicit group are because of the absence or presence of students' noticing in either group. In order to reduce the effect of listening ability, the teacher was asked to run a warmup on the basis of the related topics in talkshows to increase comprehensibility of the materials in talkshows. The researchers also were careful about choosing the materials for the maximum comprehension to occur by checking for the complexity and language familiarity of the materials. The third factor is time. Participants spent more time in implicit instruction group because of the nature of the materials. This factor may contaminate the results. Eliminating and observing these limitations can provide suggestions for further research.

\section{Appendices}

\section{A. Topic Familiarity Questionnaire}

For more details see Table 7 .

\section{B. Task Evaluation Questionnaire}

(1) To what extent is the goal or goals of the task obvious (a) to you (b) to your students?

(2) Is the task appropriate to the learners' proficiency level?

(3) To what extent does the task reflect a real-world or pedagogic rational? Is this appropriate?

(4) Is the task likely to be interesting and motivating to the students?

(5) Is there an information gap or problem which might promote a negotiation of meaning?

(6) Are the activities designed in a way which will allow learners to communicate and cooperate with others?

(7) To what extent are learners encouraged to negotiate meaning?

(8) Is the task at the appropriate level of difficulty for students? 
TABLE 6: Independent sample $t$-test on complexity of language.

\begin{tabular}{|c|c|c|c|c|c|c|c|c|c|c|}
\hline & \multicolumn{6}{|c|}{ Levene's test for equality of variances } & \multicolumn{4}{|c|}{$t$-test for equality of means } \\
\hline & & \multirow[t]{2}{*}{$F$} & \multirow[t]{2}{*}{ Sig. } & \multirow[t]{2}{*}{$t$} & \multirow[t]{2}{*}{$\mathrm{df}$} & \multirow[t]{2}{*}{$\begin{array}{l}\text { Sig. } \\
\text { (2 tailed) }\end{array}$} & \multirow[t]{2}{*}{$\begin{array}{l}\text { Mean } \\
\text { Difference }\end{array}$} & \multirow[t]{2}{*}{ Std. Error Difference } & \multicolumn{2}{|c|}{$\begin{array}{l}\text { 95\% Confidence } \\
\text { Interval of the } \\
\text { Difference }\end{array}$} \\
\hline & & & & & & & & & Lower & Lower \\
\hline \multirow{2}{*}{$\begin{array}{l}\text { Complex } \\
\text { utterance }\end{array}$} & Equal variances assumed & 2.804 & .116 & 4.451 & 14 & .001 & 3.7500 & .84251 & 1.9430 & 5.5570 \\
\hline & Equal variances not assumed & & & 4.451 & 10.7 & .001 & 3.7500 & .84251 & 1.8896 & 5.6103 \\
\hline
\end{tabular}

TABle 7: Topic Familiarity Questionnaire. Which activities are you confident at? Choose from the highest confidence to the lowest.

123

(1) Give suggestions and decide on the best suggestion

(2) Giving reasons

(3) Giving instructions

(4) Making decisions

(5) Solving problems

(6) Describing people

(7) Telling stories

(8) Completing incomplete set of information

(9) Organizing information

(10) Giving directions

(9) If not, is there any way in which the task might be modified in order to make it either easier or more challenging?

(10) Is the task realistic in terms of the resources and teacher-expertise it demands?

\section{Acknowledgments}

The authors wish to thank a number of committed people who have given this study their best shot including the authors' dear colleagues and students.

\section{References}

[1] R. Ellis, The Study of Second Language Acquisition, Oxford University Press, New York, NY, USA, 1st edition, 1994.

[2] R. Ellis and G. Barkhuizen, Analyzing Learner Language, Oxford University Press, New York, NY, USA, 1st edition, 2005.

[3] R. Ellis, "The empirical evaluation of language teaching materials," English Language Teaching Journal, vol. 51, no. 1, pp. 36-42, 1997.

[4] R. Ellis, "Task- based research and language pedagogy," Language Teaching Research, vol. 4, no. 3, pp. 193-220, 2000.

[5] R. Ellis, Task-Based Language Teaching and Learning, Oxford University press, New York, NY, USA, 1st edition, 2003.

[6] M. Bygate, "Task as context for the framing, reframing and unframing of language," System, vol. 27, no. 1, pp. 33-48, 1999.

[7] M. Bygate, "Quality of language and purpose of task: patterns of learner's language on two oral communication tasks," Language Teaching Research, vol. 3, no. 3, pp. 185-214, 1999.
[8] R. Ellis, "Measuring implicit and explicit knowledge of a second language," Studies in Second Language Acquisition, vol. 27, pp. 141-172, 2005.

[9] C. Doughty and T. Pica, "Information gap tasks: do they facilitate second language acquisition?” TESOL Quarterly, vol. 20, no. 2, pp. 305-335, 1986.

[10] R. Ellis, H. Basturkmen, and S. Loewen, "Learner uptake in communicative ESL lessons," Language Learning, vol. 51, no. 2, pp. 281-318, 2001.

[11] Y. Nakahama, L. van Lier, and A. Tyler, "Negotiation of meaning in conversational and information gap activities: a comparative discourse analysis," TESOL Quarterly, vol. 35, no. 3, pp. 377-405, 2001.

[12] K. Branden, "Effects of negotiation on language learners' output," Language Learning, vol. 47, no. 4, pp. 589-636, 1997.

[13] Z. Dornyei and J. Kormos, "The role of individual and social variables in oral task performance," Language Teaching Research, vol. 4, no. 3, pp. 275-300, 2000.

[14] D. Nunan, Designing Tasks for the Communicative Classroom, Cambridge University Press, 1989.

[15] D. Nunan, Second Language Teaching and Learning, Heinle \& Heinle, Boston, Mass, USA, 1999.

[16] R. Ellis, Implicit and Explicit Knowledge in Second Language Learning, Testing and Teaching, Multilingual Matters, 2009.

[17] H. Farhady, Research Methods in Applied Linguistics, Payame Noor University Press, Tehran, Iran, 1999. 

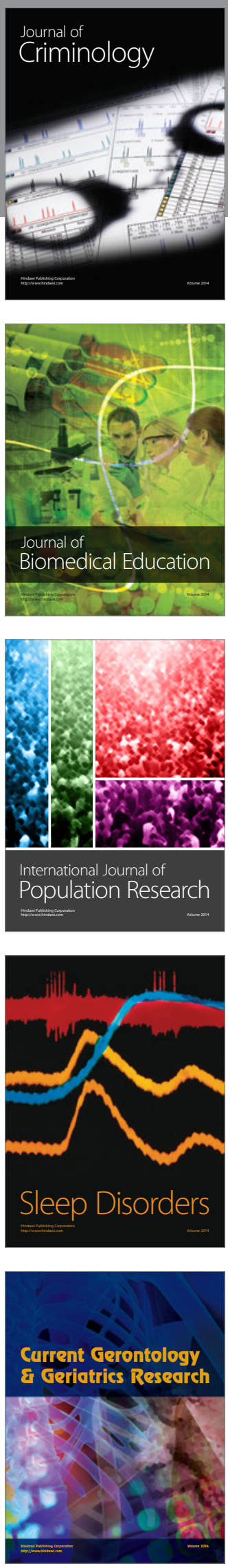
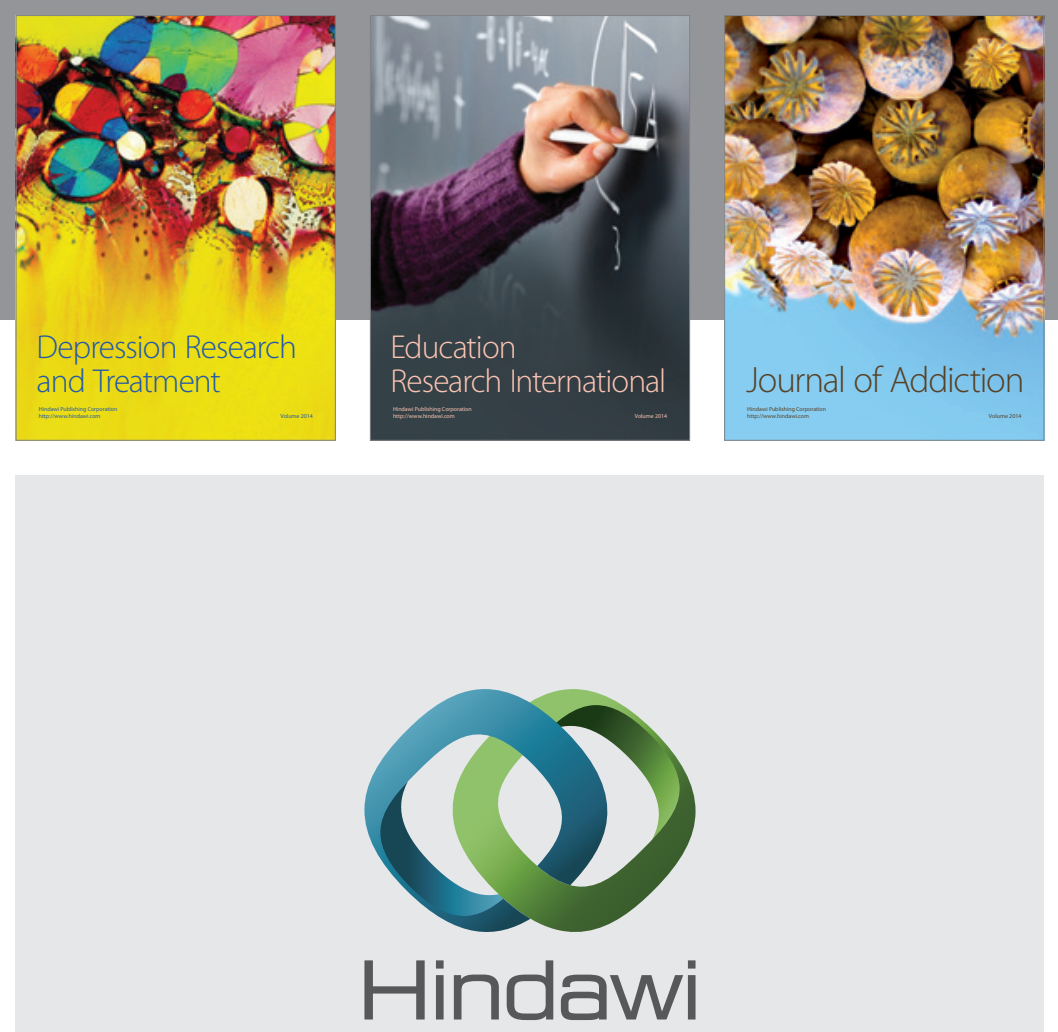

Submit your manuscripts at

http://www.hindawi.com

Child Development Research
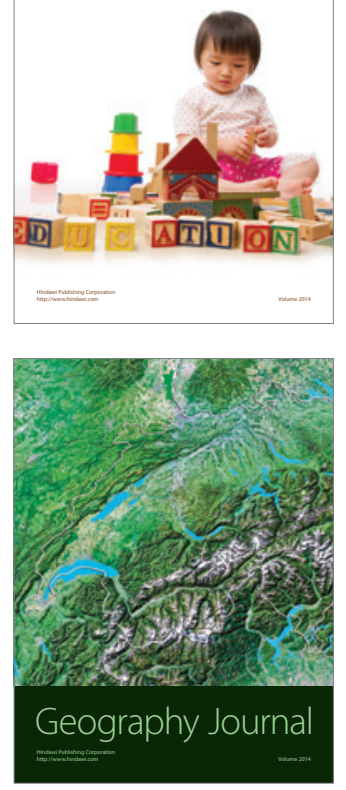

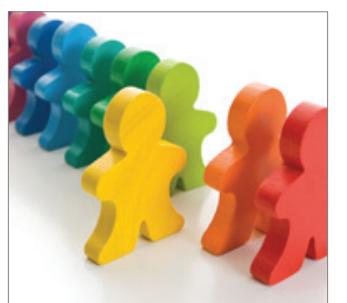

Autism

Research and Treatment
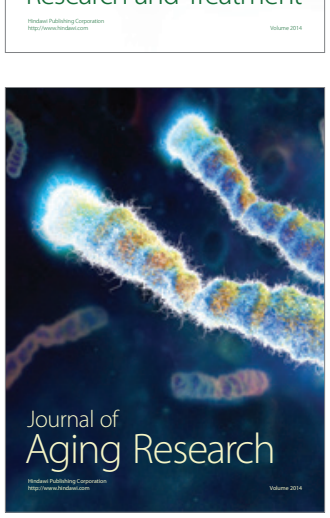
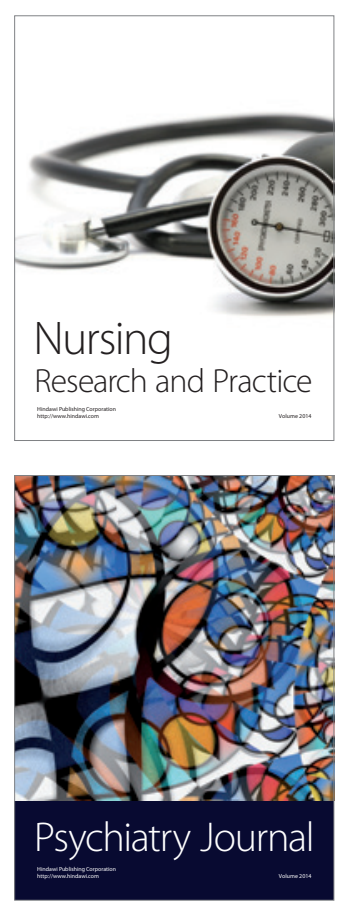
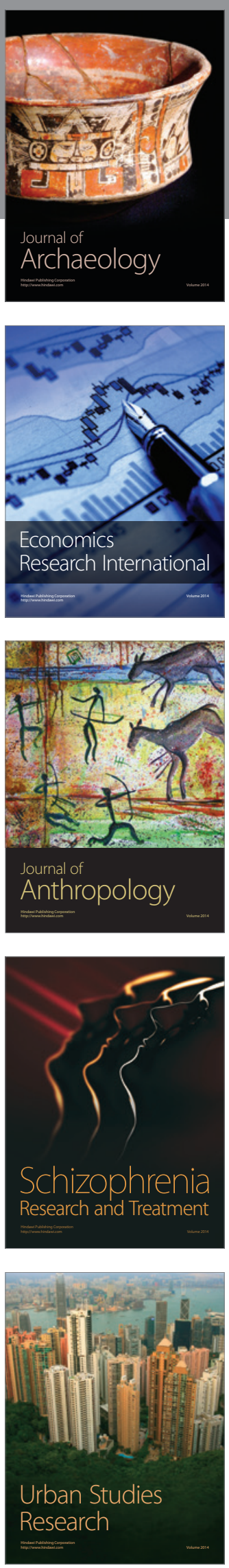